\title{
O processo de significação no tempo narrativo: uma proposta metodológica
}

\author{
Anália Keila Ribeiro ${ }^{l}$ \\ Centro Federal de Educação Tecnológica de Pernambuco
}

Maria C. D. P. Lyra

Universidade Federal de Pernambuco

\begin{abstract}
Resumo
Este trabalho propõe uma metodologia de análise considerando o tempo como conceito central na construção de significados em narrativas (Ricoeur, 1994). As bases teórico-metodológicas dão suporte à proposição de três dimensões de análise, chamadas mimesis I, II e III. Mimesis I é descrita e exemplificada. Esta primeira mimesis se refere ao necessário acordo prévio entre autor e audiência acerca do mundo da ação narrada. A análise de uma narrativa escrita por uma estudante do ensino médio acerca de sua experiência escolar provê uma ilustração de como o tempo se torna espacializado como cronotopos, constituindo o cenário para a construção de significados (Bakhtin, 1986, 2000). Tais cenários oferecem o locus no qual as possibilidades e dificuldades envolvidas na transformação e no desenvolvimento do autor criam os significados de sua experiência. Eles também fornecem elementos para a identificação de interfaces entre o desenvolvimento individual e o ambiente social e cultural no qual este desenvolvimento ocorre.
\end{abstract}

Palavras-chave: narrativa; desenvolvimento do self; tempo narrativo; experiência; significado

\begin{abstract}
Meaning-making process in the narrative time: a methodological proposal. This work proposes a methodology of analysis that takes time as central conception to the construction of narrative meanings (Ricoeur, 1994). The theoretical and methodological bases support the proposal of three dimensions of analysis called mimesis $I, I I$ and III. Mimesis I analysis is reported and exemplified. This first mimesis refers to a necessary previous agreement between an author and audience about the world of the narrated action. The analysis of a narrative written by a high school female student regarding her school experience provides an illustration of how time becomes specialized as cronotopos, constituting the scenery for meaning construction (Bakhtin, 1986, 2000). These sceneries offer the locus in which possibilities and difficulties involved in the transformation and development of the author create the meanings of his/her experience. They also provide elements to the identification of interfaces between the individual development and the socio-cultural environment where this development occurs.
\end{abstract}

Key-words: narrative; development of the self; narrative time; experience; meaning

$\mathrm{E}$ ste trabalho explicita uma proposta de análise que toma o tempo como elemento central na construção de significados em narrativas. Tendo como foco o entendimento partilhado do mundo da ação por parte do autor e da audiência, denominado mimesis $I$, ele faz parte de um trabalho de pesquisa mais amplo que elabora essa análise em mais duas dimensões: mimesis II e mimesis III (Ricoeur, 1994). Todas essas dimensões de análise se encontram assistidas pela concepção bakhtiniana (Bakhtin, 2000) de cronotopos. Considerando o cronotopos como o tempo narrativo que estrutura o tempo humano na linguagem, assume-se a narrativa como a forma privilegiada de construção de significados que dizem respeito à organização da experiência humana e à emergência de um sentido de self nessa organização. O cronotopos narrativo possibilita que o significado da experiência se constitua vinculado à história e a cultura nas quais se insere a experiência narrada. Neste artigo, são expostas as bases teórico-metodológicas da proposta e, após a apresentação sucinta das três dimensões aludidas anteriormente, a primeira delas é exemplificada.

As três dimensões referidas correspondem a processos interligados pelos quais os significados da experiência humana são constituídos narrativamente. A primeira delas, denominada mimesis I (Ricoeur, 1994), remete ao nível de significação implicado na participação mútua do autor da narrativa e de sua audiência no mesmo sistema de significados. Tal participação provê um acordo prévio sobre os processos, as relações e as 
regulações envolvidas no universo no qual se passa a narrativa, constituindo o mundo da ação narrada. O conceito ricoeuriano de mimesis I como mundo da ação comporta três aspectos a serem explorados na presente análise como estruturadores do significado narrativo: (a) a sua natureza temporal; (b) a sua trama conceitual; e (c) os seus recursos simbólicos.

A metodologia proposta foi aplicada à análise de 20 narrativas escritas por estudantes brasileiros do turno noturno de uma escola pública localizada na zona urbana da cidade do Recife. Estes estudantes faziam parte de uma turma do 3o ano do ensino médio quando da obtenção das narrativas, escritas a partir de uma tarefa proposta que solicitou aos estudantes que imaginassem uma viagem através de seus anos escolares, tal como um "relatório da viagem realizada". A análise de uma das narrativas (Participante 1) é utilizada para ilustrar o entendimento dos processos de significação envolvidos em mimesis I.

\section{Cultura, historicidade e os fundamentos temporais da subjetividade}

O que é especificamente humano foi historicamente desenvolvido por meio da cultura. Ela instaura a humanidade, isto é, ela compõe aquilo de nós que transcende os limites da natureza biológica e transforma tanto as pessoas como o mundo que nos cerca. Por meio da cultura, nós e nosso mundo nos tornamos humanos. Nas palavras de Bruner,

o divisor na evolução humana foi cruzado quando a cultura se tornou o fator principal para dar forma às mentes daqueles que viviam sob sua influência. Produto da história, e não da natureza, a cultura agora se tornou o mundo ao qual nós tínhamos que nos adaptar e o kit de ferramentas para fazer isso. (Bruner, 1997, p. 22)

A cultura se destaca da natureza e se estabelece como ambiente e instrumento necessário para o funcionamento humano na medida em que deriva de uma temporalidade diferente daquela dos fenômenos naturais (Bruner, 1997). Tal temporalidade está fundamentada na condição histórica que passa a regulamentar a existência da humanidade. Quando o registro temporal regulador da existência humana muda do tempo da natureza para o tempo da História, caracteriza-se a cultura como "fator principal para dar forma às mentes daqueles que viviam [e vivem] sob sua influência" (Bruner, 1997, p. 22). Se, portanto, a cultura institui a humanidade, o fundamento da cultura como constitutivo do que é humano advém, por sua vez, de sua historicidade intrínseca.

Sustentada numa base comum, universal, representada pela possibilidade de retomar os acontecimentos da existência, esta historicidade os relaciona numa disposição que não corresponde necessariamente à ordem exata dos acontecimentos (Abbagnano, 1998), mas a uma qualidade que estes, a priori, não possuem: o significado. A criação de significado comuta o registro temporal de natural para histórico. Esta transformação inaugura o tempo humano que se define, portanto, como uma reinvenção da ordem natural dos acontecimentos através de um encadeamento que, para além do cronológico, obedece aos ditames da mediação simbólica. Tais ditames se referem às transformações ocorridas a partir do advento do signo e da linguagem, que estabeleceu uma ordem simbólica na qual os seres humanos passaram a funcionar.
Esta ordem, como nos lembra Vigotski (2000), ao proporcionar o encontro entre pensamento e linguagem, acarretou mudanças qualitativas na constituição da mente humana, além de funcionar como instrumental para o relacionamento entre os seres humanos e seu mundo. Um aspecto fundamental dessas mudanças se refere à qualidade de historicidade de que o tempo se revestiu, pois, por meio do símbolo, se tornou possível dizer os tempos da existência humana, retomá-los e partilhá-los com outros seres humanos.

Sobre esta base, as diversas sociedades construíram diferentes formas de organizar o tempo e de conduzir-se historicamente. Tais formas de organizar o tempo implicam trocas entre os indivíduos possibilitando, na retomada dos acontecimentos, o processo de subjetivação. Desta maneira, instaura-se um ambiente no qual se dão as relações comunicativas entre os participantes de uma sociedade e onde proliferam diversos encaminhamentos históricos instituintes da subjetividade (Lightfoot, 1997). Assim, pelas mãos da historicidade, nós, não apenas inventamos o tempo, mas somos por ele inventados ou constituídos.

Como elemento que integra a constituição da subjetividade, o tempo humano adquire o caráter de fenômeno psicológico no qual eventos, lugares, sentimentos, signos, percepções, propósitos, interações, opiniões, crenças e demais esferas humanas são desenvolvidas, tanto individualmente como conjuntamente. Dessa forma, ele constitui tanto uma evidência quanto um meio pelo qual nossas experiências estão conectadas aos sistemas simbólicos nos quais os significados são criados e negociados (Bruner, 2001). Considerar, portanto, o tempo parece ser essencial para entender a emergência da subjetividade nas interfaces entre a experiência humana individual e os processos mais amplos de construção de significado da mediação simbólica. A narrativa, como um discurso eminentemente temporal, assume um lugar de destaque tanto para análise do processo de significação como da subjetividade.

\section{Narrativa e construção temporal dos significados da experiência}

A narrativa está presente em todas as culturas humanas conhecidas (Freeman, 1998; Macintyre, 1981). Nós, os seres humanos, estamos sempre contando e/ou ouvindo histórias. Desde muito cedo na infância, conseguimos articular nosso discurso narrativamente (Miller, Potts, Fung, Hoogstra, \& Mintz, 1990; Nelson, 1989). Além disso, narrativas estão em toda parte: nossos pais e avós contam histórias, nossos vizinhos relatam algo que lhes aconteceu, a televisão nos conta suas versões dos fatos na forma de reportagem e nos fornecem ficções na forma de filmes e novelas. Lemos romances, contos, cordel. Ouvimos as histórias dos amigos, acerca deles mesmos e dos outros. Relatar a experiência é uma das formas básicas pelas quais nós nos comunicamos uns com os outros (Polkinghorne, 1988). Isso levanta a questão de por que narramos, ou seja, o que faz com que a narrativa seja tão presente nas diversas culturas humanas e tão imbricada nas nossas vidas? Nós narramos para significar a nossa experiência e para negociá-la nos sistemas de significados que lhes fornecem os contextos (Sarbin, 1986). Em outras palavras, narramos porque essa é a forma básica de significação da experiência (Polkinghorne, 1988). É nisso que 
reside a sua força pervasiva.

Entretanto, outra questão é levantada por esta afirmação: como a narrativa faz isso? Que qualidades lhe possibilitam realizar o trabalho de construir significados da experiência humana? Para responder esta questão, se faz necessário voltar à natureza temporal da narrativa porque, se o tempo humano é, como dito anteriormente, um processo de ordenação por meio do qual reinventamos os acontecimentos em termos do significado, a narrativa é, prioritariamente, a forma discursiva assumida por este tempo. Por isso, tempo e narrativa são inseparáveis; como diz Ricoeur: "O tempo torna-se tempo humano na medida em que está articulado de modo narrativo; em compensação, a narrativa é significativa na medida em que esboça traços da experiência temporal" (Ricoeur, 1994, p. 15).

\section{Cronotopos: o tempo narrativo como perspectiva de análise}

Bakhtin (2000) explica a evolução histórica do romance com base no aparecimento de formas inovadoras de relatar o desenvolvimento do herói vinculadas à abordagem temporal. Para ele, o tempo que mostra a complexidade do desenvolvimento do herói é o tempo histórico presente nos romances de formação chamados de bildungsroman. O surgimento desse tempo possibilitou realizar, em termos da narrativa, conexões entre o herói e o mundo no qual a ação ocorre porque ele possui espacialidade, o que permite que o relato remeta, concomitantemente, ao tempo e ao espaço da ação. A espacialidade do tempo histórico resultou numa perspectiva em que é possível vislumbrar o desenvolvimento em seu ambiente, em seu mundo, porque "o tempo é introduzido no homem, entra na sua imagem, mudando de forma fundamental o significado de todos os aspectos do destino e da vida" (Bakhtin, 1986, p. 21). Este tempo, responde, portanto, por significados que dizem respeito ao desenvolvimento das pessoas, pois traça uma perspectiva dos destinos das vidas nas suas dimensões pessoal e social.

Tal perspectiva, construída por meio da espacialização do tempo é denominada cronotopos. Portanto, o cronotopos bakhtiniano, antes de ser inerente à ação propriamente dita, é concebido como um processo psicológico referente à pessoa que está construindo significados de uma experiência ao contar uma história e ao recebê-la.

Bakhtin conceitua cronotopos como:

\begin{abstract}
A habilidade para ver o tempo, ler o tempo, em um todo espacial do mundo e, por outro lado, perceber o preenchimento do espaço não como um pano de fundo imóvel, um dado que é completado de uma vez por todas, mas como uma inteireza emergente, um evento - esta é a habilidade para ler em todas as coisas os sinais que mostram o tempo no seu curso, começando com a natureza e terminando com os costumes e idéias humanas (...) A emergência do homem é capturada no tempo histórico real, com todas as suas necessidades, sua completude, seu futuro, e sua natureza profundamente cronotópica. (Bakhtin, 1986, p.23)
\end{abstract}

Nesse sentido, o cronotopos pode ser visto como um método de captar o tempo humano de tal forma que os significados construídos explicitem a emergência do herói na dinâmica de seu ambiente, tanto na narração quanto na interpretação de uma narrativa por parte da audiência. Foi essa perspectiva cronotópica que possibilitou a Bakhtin identificar o tempo histórico nos romances de Goethe e Dostoyevsky. Assim, Bakhtin não apenas demonstrou o surgimento do cronotopos na literatura, mas o fez procurando a espacialidade do tempo e, desta forma, remetendo aos conteúdos da experiência a ser significada e às relações que demandam a significação destes conteúdos que a suportam. Dessa forma, abre-se uma porta para vislumbrar o desenvolvimento do herói que remete à emergência da subjetividade. Essa é a base sobre a qual se assenta a nossa argumentação de que o tempo histórico, representado como cronotopos nos estudos bakhtinianos, pode fundamentar uma metodologia de análise de dados para apreender a construção de significados da experiência em narrativas.

\section{O tempo na alma como tríplice temporalidade}

Concebendo a narrativa como um processo no qual os significados emergem a partir de uma relação de interdependência entre o processo de construção do enredo e a configuração temporal desse enredo, Ricoeur explora essa relação na sua obra Tempo e Narrativa (Ricoeur, 1994). Neste artigo, nos referimos mais especificamente ao Tomo I da referida obra. Partindo de dois pólos distintos da literatura filosófica, separados um do outro por séculos e por universos distintos, ele explora a narrativa a partir da teoria da construção do enredo na Poética de Aristóteles e o tempo a partir das teorizações acerca do tempo nas Confissões de Santo Agostinho. A contribuição da concepção agostiniana de tempo para o estudo da interdependência entre tempo e narrativa é descrita a seguir.

Duas idéias centrais da concepção agostiniana do tempo fundamentam as suas possibilidades metodológicas para o estudo da narrativa. Primeiro, ao definir o tempo, não como um fenômeno físico, mas como um processo da alma, Santo Agostinho desloca a concepção de tempo de uma materialidade externa vinculada aos fenômenos físicos para a dimensão psicológica. Para ele, o tempo é um processo inerente às pessoas, um dispositivo psíquico que organiza a experiência. Neste tempo está implicada sua expressão na linguagem, na medida da necessidade que os seres humanos têm de falar de fatos acontecidos, acontecendo e por acontecer.

Dessa primeira idéia de tempo como um fenômeno da alma, decorre a segunda que diz que, se o tempo se passa na alma, ele não pode existir como três: passado, presente e futuro, A alma só comporta a realidade presente. O passado e o futuro são fenômenos exteriores a ela, pertencem à factualidade material dos acontecimentos. $\mathrm{Na}$ alma, os fatos acontecidos num tempo anterior podem aparecer como memória, caracterizando-se como a apresentação presente daquele passado: o presente do passado. Os fatos que se supõem surgir no futuro podem estar presentes na alma como expectativa: o presente do futuro. Os fatos do presente propriamente dito transitam na alma como o presente do presente. Assim, na alma há um só tempo: o presente, que se desdobra em três: o presente do passado, o presente do presente e o presente do futuro. Em suma, o passado é reapresentado na alma como memória, o presente é a atenção a cada momento e o futuro sempre está presente em forma de expectativa. 
Essa perspectiva, por sutil que seja, traz três contribuições essenciais para a relação entre tempo e narrativa. A primeira delas é que, ao se passar na alma e depender da linguagem, o tempo agostiniano se aproxima dos processos da narrativa, que também é um fenômeno psicológico próprio da linguagem humana. A segunda conseqüência dessa tríplice temporalidade inspira a idéia de que a narrativa é um processo triplamente dimensionado, já que baseado numa temporalidade que tem essa natureza. A terceira contribuição é o encadeamento desses três presentes possibilitando compor os fatos da experiência sem que a factualidade de um tempo cronológico seja determinante para os significados construídos. Dessa forma, é possível estabelecer diversas relações entre passado, presente e futuro que aparecem, então, encadeados por uma lógica que transcende a mera cronologia. Tais relações falam de conseqüências, intenções, mutualidades, oposições, entre outras características. Elas até mesmo consideram conjuntamente elementos díspares, oponentes e/ou excludentes num construto significativo. Cada narrativa, ao ser composta, apresenta uma conjugação de elementos e processos conduzindo a estados desejados de felicidade, esses elementos são chamados de concordâncias. Apresenta, também, elementos e processos que tendem a conduzir a história a estados de infelicidade, as discordâncias. Neste sentido, a narrativa é sempre uma composição concordante discordante porque ela negocia, nos sistemas simbólicos, as contradições da experiência.

\section{A tríplice mimesis: explicitando os fundamentos da proposta metodológica para a análise de narrativas}

Em Aristóteles, Ricoeur encontra o conceito de narrativa como mimesis da experiência. Todavia, assim como para Aristóteles, para Ricoeur (1994), o conceito de mimesis não é o de pura imitação, refere-se, antes, a um processo de criação e recriação da experiência que toma a forma da ação narrada. Nas suas palavras, "se continuamos a traduzir mimesis por imitação, deve-se entender totalmente o contrário do decalque de um real preexistente e falar de imitação criadora" (p. 76).

Baseado nessa idéia, Ricoeur entende a narrativa não como um produto, mas como um processo que prossegue além da construção de um enredo específico. A narrativa tem seu ponto de partida na compreensão desenvolvida historicamente e partilhada pelas pessoas acerca de si e do mundo; e seu ponto de chegada na ampliação, na transformação e no aprofundamento dessa compreensão. Com os pontos de partida e de chegada identificados, Ricoeur se lança à tarefa de estabelecer as relações entre tempo e narrativa. Esta relação se baseia no argumento de que a narrativa é um recurso do tempo humano para organizar, em termos dos processos psicológicos humanos, a experiência que, de outra forma, permaneceria espalhada na opacidade da ausência da cultura e dos símbolos. Ao relacionar o tempo humano à narrativa, Ricoeur está, de fato, explicitando um caminho pelo qual a mediação simbólica libera o tempo humano dos limites da materialidade e o constitui como recurso organizativo da experiência em vista do significado.

Para explorar esse caminho, o autor define o processo narrativo como uma tríplice mimesis: mimesis $I$, mimesis $I I \mathrm{e}$ mimesis III. Cada uma delas guia a inteligibilidade narrativa, ou seja, a sua capacidade de construir significados. A narrativa, então, se apresenta como um discurso que organiza, num todo temporal, as experiências dos seres humanos, levando-as à arena simbólica num processo de criação e de negociação. Esse é o sentido da mimesis da experiência realizada na narrativa.

Os significados elaborados pelo primeiro nível de imitação criativa da experiência, mimesis I, se referem ao entendimento partilhado das relações postas para o desenrolar da experiência - o mundo da ação. A partilha deste entendimento comporta os três aspectos fundamentais já referidos anteriormente: (a) a sua natureza temporal; (b) a sua trama conceitual; e (c) os seus recursos simbólicos. É sobre essa partilha que se baseia primeiramente qualquer possibilidade de inteligibilidade narrativa. Para que os significados de uma experiência sejam partilhados, é necessário um acordo prévio entre o autor da narrativa e as pessoas que vão recebê-la - a audiência - sobre as qualidades, regulações e possibilidades dos cenários nos quais a ação se passa.

Em mimesis II os significados se referem à construção de uma trama na qual a ação é relatada a partir da organização das relações entre os elementos considerados importantes para a experiência. Nessa trama, concordâncias e discordâncias aparecem entrelaçadas, tornando a narrativa concordante e discordante ao mesmo tempo. Por isso, Ricoeur (1994) se refere à narrativa como uma composição concordante discordante. Esse entrelaçamento, denominado de drama narrativo, media as relações postas pelo mundo da ação com as particularidades da experiência específica que se quer relatar. Em outras palavras, mimesis II é o trabalho de enredar fatos e pessoas na trama narrativa. É da construção do enredo ${ }^{2}$ o trabalho de juntar diferentes acontecimentos, envolvendo elementos distintos como agentes, finalidades, circunstâncias e interações, num processo que conduza a experiência a apresentar-se com inteireza nos sistemas de significados da cultura humana.

Em mimesis III, entra em jogo o trabalho de interpretação feito pela audiência na recepção da narrativa. Ao recriar e tornar uma experiência significativa, a narrativa indica as formas pelas quais os significados construídos podem ser entendidos e aceitos. Nesse sentido, a audiência funciona como o fiel da balança no processo de significação da experiência porque é o trabalho interpretativo desta que define aquilo que de uma experiência é legitimado. Para isso, a audiência considera encaminhamentos dados à conjunção de fatores diferentes como a abstração e a concretude, a novidade e o já conhecido, a pessoa e o ambiente, as emoções e a razão. Tais conjunções, em termos gerais, devem conduzir a audiência através da história.

Tendo sido fundamentada a proposta metodológica, seguese a explicitação e a exemplificação de sua primeira etapa, mimesis I.

\section{Mimesis I e o entendimento partilhado do mundo da ação: proposta metodológica}

Partindo do pressuposto de que o autor e a audiência participam do mesmo entendimento sobre como uma experiência pode ser significada, a análise em mimesis I se volta para o acordo 
partilhado entre autor e audiência. Este acordo versa sobre os requisitos estruturais para o processo de narrar uma experiência, no qual o cronotopos se configura em um processo narrativo. Tais requisitos são: (a) a sua natureza temporal; (b) a sua trama conceitual; e (c) os seus recursos simbólicos.

\section{A natureza temporal do mundo da ação leva à identificação dos incidentes narrativos}

A temporalidade da ação narrada subsidia um sentido de todo a partir de um encadeamento de unidades temporais menores que chamamos de incidentes narrativos. Uma história deve encadear acontecimentos que, de outra forma, apareceriam fragmentados. Pertencer a uma história qualifica fatos, circunstâncias, falas, pessoas e sentimentos com novos significados porque os relaciona ao todo da história e os encadeia numa lógica temporal que vai de um começo para um fim. Entretanto, este construto temporal é encadeado em unidades lógicas menores, os incidentes narrativos. Então, o primeiro passo em mimesis I consistiu em identificar as expressões de tempo na narrativa e, por meio delas, os incidentes narrativos.

Os incidentes narrativos são, portanto, unidades temporais de significação dispostas sucessivamente na medida em que vão desvelando os acontecimentos mutuamente integrados como parte do todo narrativo. Cada uma dessas unidades é marcada por uma ação principal a que se agregam elementos da trama conceitual. O encadeamento dos incidentes retrata as transformações ocorridas no desenvolvimento da experiência. Cada nova unidade caracteriza um passo no desenrolar da experiência relatada, enfatizando, assim, os aspectos significativos para a história.

Este processo é assistido por uma rede de tempos verbais, advérbios de tempo e expressões de tempo em geral, chamados de marcadores temporais. Estes funcionam na narrativa como organizadores dos incidentes. Na presente análise, eles forneceram as pistas para a identificação dos incidentes narrativos, bem como das mudanças desencadeadas de um incidente para outro. Os trechos da narrativa do Participante 1, exemplificam, a seguir, os marcadores temporais, analisados depois como parte de dois incidentes diferentes.

\section{Exemplo 1: marcadores temporais}

Tudo começou quando eu tinha sete anos, troquei a chupeta por um caderno. Não foi nada fácil, pois, nasci no sertão, lá onde o diabo perdeu as botas não tinha escola nem professor qualificado, quem ensinava era a minha tia materna, tia Ocina que às vezes não tinha giz e ela escrevia com carvão,... mas minha experiência teve que ter fim rapidinho, pois minha mãe casou e começou a ter filhos todo ano, e eu, como era a mais velha tinha que tomar conta dos pirralhos. (Participante 1)

Nesse trecho, conseguimos vislumbrar o encadeamento de dois incidentes: 1 e 2 .

\section{Exemplo 2: incidentes identificados}

Incidente 1: Tudo começou quando eu tinha 7 anos, troquei a chupeta por um caderno. Não foi nada fácil, pois, nasci no sertão, lá onde o diabo perdeu as botas não tinha escola nem professor qualificado, quem ensinava era a minha tia materna, tia Ocina que às vezes não tinha giz e ela escrevia com carvão,...

Incidente 2: ...mas minha experiência teve que ter fim rapidinho, pois minha mãe casou e começou a ter filhos todo ano, e eu, como era a mais velha tinha que tomar conta dos pirralhos.

Cada um deles é assistido por marcadores temporais que desenvolvem as qualidades temporais presentes nas ações narradas. Estes marcadores temporais dão o suporte para a identificação dos incidentes, especialmente quando a narrativa apresenta expressões adverbiais que comutam a qualidade do tempo narrado. A expressão temporal no primeiro incidente: quando eu tinha 7 anos, data o início da ação; já no segundo, o advérbio rapidinho, no diminutivo, imprime um caráter não apenas expresso, mas brusco, à mudança no rumo da história, marcando assim, não apenas o encerramento do incidente anterior e o início de outro, como também a qualidade do tempo da ação pertinente a esta mudança de um para outro incidente. Assim, a partir do andamento das ações e da qualidade temporal conferida pelos marcadores aos incidentes, pôde-se inferir a emergência de significados que se relacionam temporalmente com os componentes dessas ações e as relações entre eles numa trama conceitual.

\section{A trama conceitual: estruturação dos elementos semânticos da ação}

A temporalidade da trama conceitual tem o caráter semântico do tempo histórico. A historicidade da trama conceitual é permeada pelas possibilidades interpretativas que a linguagem provê às experiências que narramos. Tais possibilidades são guiadas pela escolha e composição de alguns elementos que, ao longo dos incidentes respondem por questões como: quem? onde? por quê? o quê? como? para quê? com quem? contra quem? (Ricoeur, 1994, p. 55). Na narrativa, esses elementos ganham significados que se referem não apenas a eles mesmos, mas ao conjunto das ações narradas.

Dessa forma, são estabelecidas relações dentro da narrativa que dizem respeito a: (a) metas: uma ação implica finalidades, na medida em que há sempre uma idéia de futuro envolvida em nossas ações; (b) motivos: nós agimos movidos por crenças, desejos, intenções, convicções que impulsionam o fazer humano; (c) agente: não existe ação sem que um agente a tenha realizado, alguém atuou de alguma forma; (d) circunstâncias: uma ação não acontece isolada, ela está sempre inserida em suas circunstâncias; (e) interação: porque sociais, as ações sempre assumem um caráter relacional; (f) desfecho: uma ação é sempre levada a um sentido de fim, a um fechamento finalizadorEssas relações, resultantes da organização temporal dos elementos acima mencionados, são, precisamente, a trama conceitual da narrativa que integra a experiência na forma de ações guardando entre si relações significativas.

A identificação das relações dessa trama nos incidentes narrativos é o trabalho desta parte da análise. Note-se que nem sempre todas as relações estão presentes em cada incidente, pois os mesmos, enquanto apontam para e compõem o todo da narrativa, continuam se caracterizando como parte do todo da narrativa e distintas contribuições para o desenrolar da história. 
No exemplo 3, observamos, na análise dos incidentes 1 e 2, a identificação dos elementos da trama conceitual.

Exemplo 3: identificação de elementos da trama conceitual Incidente 1: Tudo começou quando eu tinha 7 anos, troquei a chupeta por um caderno (ação que caracteriza o incidente). Não foi nada fácil, pois, nasci no sertão, lá onde o diabo perdeu as botas não tinha escola nem professor qualificado (circunstância), quem ensinava era a minha tia materna, tia Ocina (interação) que às vezes não tinha giz e ela escrevia com carvão (circunstância),...

Incidente 2: mas minha experiência teve que ter fim (ação que caracteriza o incidente) rapidinho, pois minha mãe (interação) casou e começou a ter filhos todo ano (motivo), e eu, como era a mais velha tinha que tomar conta dos pirralhos (desfecho).

\section{Os recursos simbólicos: justificação e avaliação como ética da experiência}

O trecho narrativo acima, como os demais, implica na articulação de signos, que são, por sua vez, públicos e sistêmicos. Disso deriva uma normatização da experiência humana a ser considerada. Concordamos com Valsiner (2000), quando explica a gênese de tal normatização da seguinte forma: "os seres humanos, quando experimentam uma situação em conjunto, criam um entendimento conjunto da situação que se torna consensualmente validado e começa a funcionar como uma norma social" (p. 56).

Essa norma social adquire a função de um sistema que articula os signos disponíveis para garantir que a ação possa ser avaliada e justificada. A avaliação e a justificação de uma ação estão relacionadas aos aspectos éticos da experiência. Estes aspectos, que emergem por meio de recursos simbólicos, sugerem a impossibilidade de neutralidade nas ações humanas. O comprometimento ético é parte integrante da negociação dos significados nas narrativas. Do trecho acima, o incidente 1 provê um exemplo de como a ação pode ser avaliada ou justificada na narrativa. No exemplo 4, observamos então como esses recursos simbólicos adquirem um caráter de avaliação e justificativa.

Exemplo 4: incidente narrativo e recursos simbólicos Incidente 1: Tudo começou quando eu tinha 7 anos, troquei a chupeta por um caderno. Não foi nada fácil, pois, nasci no sertão, lá onde o diabo perdeu as botas não tinha escola nem professor qualificado, quem ensinava era a minha tia materna, tia Ocina que às vezes não tinha giz e ela escrevia com carvão,...

Recurso simbólico, avaliação e justificativa: Não foi nada fácil, pois, nasci no sertão, lá onde o diabo perdeu as botas

Apesar de todo o relato, pelo seu próprio andamento, escolha de palavras, densidade, relação entre os personagens já propor indicativos para avaliação e justificativa, este trecho, em particular, explicita que a experiência relatada - a escolarização - é de difícil realização. A idéia predominante de dificuldade é justificada pela geografia da experiência, que remete a um lugar esmo, suscitando uma idéia de abandono: nasci no sertão, lá onde o diabo perdeu as botas.

\section{A organização cronotópica}

Os três elementos de mimesis I: natureza temporal, trama conceitual e recursos simbólicos, são agora considerados conjuntamente para demonstrar a identificação da organização cronotópica da narrativa. Esta organização exibe as relações entre esses elementos num tempo espacializado. A visualização desta organização foi feita por meio de tabela na qual as colunas representam o arranjo temporal através dos incidentes narrativos e as linhas apresentam os elementos da trama conceitual, assim como os recursos simbólicos Desta forma, foi possível visualizar a organização cronotópica e abstrair desta os espaços que constituem cenários em torno dos quais autor e audiência construíram um universo específico. Neste universo específico, a narrativa reinventa a experiência na sua unicidade e também a partilha ao inseri-la no mundo da significação entre parceiros. A Tabela 1 exibe a síntese acima descrita.

\section{Espaços de significação: cenários do mundo da ação desenhados pelo tempo narrativo}

$\mathrm{O}$ encadeamento dos incidentes narrativos, bem como a distribuição das relações da trama conceitual e dos recursos simbólicos apresentados na Tabela 1, fornecem a base para a última etapa de análise em mimesis I, que consistiu em identificar, no tempo narrativo, os espaços que compõem o mundo da ação narrada, ou seja, os seus cenários. Tais cenários não se referem primariamente a definições meramente físicas do espaço, eles remetem a construções de nichos sociais nos quais relações pessoais e interpessoais específicas são postas a funcionar.

Assim, o processo de significação da experiência se situa, ao mesmo tempo, no âmbito do indivíduo e naquele da cultura, integrando, desta forma, a coletividade em que esse indivíduo está inserido; a experiência específica, os dramas e alegrias humanas, criam significação nos sistemas simbólicos disponíveis. Para isso, são requeridas as arenas simbólicas onde o tempo humano, como fenômeno psicológico ancorado num contexto social, situa as relações nas quais o agente vive sua experiência (Hermans, 1996), provendo-lhe um terreno e uma textura. Sendo assim, propõe-se que a análise desses cenários lance luzes sobre as configurações sociais em jogo nesses dramas e no desenvolvimento das pessoas neles. Dessa forma, a espacialidade do tempo na narrativa propicia a descrição dos contextos culturais para o desenrolar de uma história específica e, por meio dessa descrição, situa na cultura o diálogo do self emergindo nessa história.

$\mathrm{Na}$ narrativa que exemplifica a metodologia proposta (narrativa do Participante 1), são identificados vários espaços nos quais ocorre a trama de onde emergem os significados propostos pelo relato. Nela, a construção de significados vai de espaços que remetem a uma bem delimitada individualidade (entendida como espaço individual) até o território da generalização (ou seja, espaço de generalização), passando pelas questões da escola, da organização familiar e das condições de trabalho. Além isso, ao longo da narrativa, à medida que novos incidentes se desenrolam, o foco narrativo se move de espaço para espaço ou inter-relaciona dois ou mais espaços. 
Tabela 1

A organização cronotópica - incidentes narrativos (participante 1) organizados por meio dos componentes do mundo da ação

\begin{tabular}{|c|c|c|c|c|c|c|c|}
\hline incidentes & 1 & 2 & 3 & 4 & 5 & 6 & 7 \\
\hline $\begin{array}{l}\text { principal } \\
\text { marcador } \\
\text { temporal }\end{array}$ & $\begin{array}{l}\text { quando eu tinha } \\
7 \text { anos }\end{array}$ & rapidinho & durante 3 anos & $\begin{array}{l}\text { quando chegava } \\
\text { o meio dia }\end{array}$ & aos 15 anos & aos 19 anos & desde então \\
\hline ação & $\begin{array}{l}\text { tudo começou } \\
\text { troquei a chupeta } \\
\text { por um caderno }\end{array}$ & $\begin{array}{l}\text { minha } \\
\text { experiência teve } \\
\text { que ter fim }\end{array}$ & $\begin{array}{l}\text { agüentei ir a } \\
\text { escola }\end{array}$ & ia à escola & $\begin{array}{l}\text { vim para o } \\
\text { Recife }\end{array}$ & $\begin{array}{l}\text { voltei a estudar } \\
\text { vim estudar aqui } \\
\text { no regueira costa }\end{array}$ & estou aqui \\
\hline
\end{tabular}

\begin{tabular}{|c|c|c|c|c|c|c|c|}
\hline \multicolumn{8}{|c|}{ trama conceitual } \\
\hline meta & & & & & $\begin{array}{l}\text { foi trabalho } \\
\text { como doméstica }\end{array}$ & & \\
\hline motivo & & $\begin{array}{l}\text { e eu tinha que } \\
\text { tomar conta dos } \\
\text { pirralhos }\end{array}$ & & & & & \\
\hline agente & narrador - eu & minha mãe & narrador - eu & narrador - eu & narrador - eu & narrador - eu & narrador - eu \\
\hline circunstâncias & $\begin{array}{l}\text { não tinha giz, } \\
\text { ela escrevia } \\
\text { com carvão, } \\
\text { não tinha escola } \\
\text { nem professor } \\
\text { qualificado }\end{array}$ & $\begin{array}{l}\text { minha mãe casou } \\
\text { e começou a ter } \\
\text { filhos todo ano }\end{array}$ & $\begin{array}{l}\text { minha mãe me } \\
\text { levava para o } \\
\text { roçado para } \\
\text { cuidar dos filhos } \\
\text { dela }\end{array}$ & $\begin{array}{l}\text { era na casa da } \\
\text { minha tia, do } \\
\text { roçado para a } \\
\text { escola tinha } 6 \\
\text { km de distância }\end{array}$ & $\begin{array}{l}\text { fugida da minha } \\
\text { mãe / }\end{array}$ & $\begin{array}{l}\text { fiz supletivo de } \\
1 \text { a a 4a série } \\
\text { como lá só tinha } \\
\text { até a } 4 \text { a série }\end{array}$ & \\
\hline interação & $\begin{array}{l}\text { minha tia } \\
\text { materna Ocina } \\
\text { ensinava }\end{array}$ & & & & & $\begin{array}{l}\text { aprendi muito } \\
\text { com a professora } \\
\text { fátima, } \\
\text { inesquecível }\end{array}$ & \\
\hline desfecho & & & & & & & $\begin{array}{l}\text { e o meu } \\
\text { aprendizado, } \\
\text { você conclua. }\end{array}$ \\
\hline \multicolumn{8}{|c|}{ recursos simbólicos } \\
\hline & $\begin{array}{l}\text { não foi nada fácil } \\
\text { nasci no sertão } \\
\text { onde o diabo } \\
\text { perdeu as botas }\end{array}$ & como mais velha & & & & & $\begin{array}{l}\text { eu lhe digo, não } \\
\text { aprendi quase } \\
\text { nada em questão } \\
\text { de didática, mas } \\
\text { lição de vida } \\
\text { aprendi bastante, } \\
\text { mas não sei } \\
\text { expressar }\end{array}$ \\
\hline
\end{tabular}

A Tabela 1, apresentada anteriormente, mostra como, no primeiro incidente, os significados da experiência escolar do agente são derivados de um interjogo entre os espaços da individualidade e da escola propriamente dita. No segundo incidente, o espaço familiar contextualiza significados representados como ameaça à experiência. Nos incidentes seguintes, terceiro e quarto, tais significados são levados à sua carga dramática máxima quando o agente insere o diálogo entre a sua individualidade, os problemas familiares e a luta pela continuidade da experiência escolar que, apesar dos seus esforços, se apresenta cada vez mais distante. Esta distância vem, até mesmo, representada geograficamente: "do roçado para a escola tinha $6 \mathrm{Km}$ de distância" (Tabela 1). No quinto incidente, a iniciativa individual do agente se coloca como decisiva para reverter o curso da história e para fazer aparecer novos lugares representados pela vinda do agente para Recife e pelo surgimento do espaço do trabalho. Nestes novos espaços, o agente pode superar a ameaça à experiência escolar. Finalmente, os dois últimos incidentes focalizam o interjogo entre o espaço escolar e o espaço individual, voltando o foco da narrativa para os mesmos espaços do incidente 1 (Tabela 1), que inicia a história. O agente, então, se permite ampliar os significados construídos para um nível de generalização que sintetiza e amplia os significados construídos na história.

\section{Conclusão}

A constituição temporal da narrativa destaca a ligação intrínseca entre a forma como os seres humanos experimentam o tempo e os processos de significação presentes na narração dessa experiência. A narrativa fornece a forma lingüística do tempo humano que inclui, mas não pode ser reduzida a uma cronologia porque a experiência humana é recriada como significação nos processos narrativos inerentes à mediação simbólica. A narrativa articula, dessa forma, a experiência individual com a história cultural da humanidade, tornando-a partilhada. Tal articulação requer que o tempo humano, na sua forma narrativa, selecione e organize os fatos da experiência. Esta seleção faz com que a ação narrada possa ser, concomitantemente, entendida como individual e única, mas também coletiva, porque inserida em 
contextos simbólicos que pertencem à história cultural da humanidade.

Concebida e analisada dessa maneira, a narrativa integra características e temas pertinentes ao estudo do desenvolvimento humano, tais como: (1) as relações entre o indivíduo e o seu ambiente; (2) o processo histórico desse desenvolvimento; (3) a caracterização do mundo no qual o indivíduo se desenvolve; (4) a dinâmica de transformação desse mundo e suas relações com a emergência individual; e (5) a concepção do indivíduo acerca do seu desenvolvimento. O desafio metodológico de considerar o tempo narrativo na construção dos significados contribui, justamente, para a pesquisa que versa sobre as características e temas acima enumerados.

O ponto crucial para o entendimento da natureza do tempo narrativo se refere à possibilidade de compreensão dos processos pelos quais os significados da experiência humana são construídos. A concepção do tempo narrativo como cronotopos torna possível seguir o fio condutor desses processos. É proposta, assim, uma metodologia que, começando pelo entendimento do mundo da ação como primeiro nível de significação proporcionado pela narrativa (mimesis I, aqui exemplificada), passa pela construção do enredo (mimesis II) e termina com a recepção da narrativa por parte de uma audiência (mimesis III). Neste artigo, o primeiro nível - mimesis I - refere-se ao posicionamento da experiência em determinados contextos que constituem os espaços ou cenários dessa experiência, ou seja o seu locus. Compreender como esses cenários são entendidos pelo autor e compostos narrativamente é ir na direção de identificar como os indivíduos interpretam as relações históricas e culturais que informam suas experiências sociais, identificando as articulações entre estas relações e o desenvolvimento de sua experiência. Trata-se de abordar os processos de significação naquilo que os constituem como individuais e coletivos. No caso específico da narrativa que exemplificou a metodologia proposta neste trabalho, são abordados, por meio da sua organização cronotópica, os vários cenários envolvidos no abandono escolar, assim como no retorno do agente à experiência. Por meio da análise desses cenários e das relações a eles pertinentes, são vislumbradas possibilidades e dificuldades ou barreiras para a transformação e desenvolvimento do sujeito apresentadas pela experiência em foco, no caso, a experiência escolar. Neste sentido, a análise da narrativa fornece elementos para a identificação de interfaces entre o desenvolvimento individual e o ambiente social e cultural no qual este desenvolvimento ocorre.

\section{Referências}

Abbagnano, N. (1998). Dicionário de Filosofia (A. Bosi, Trad., 2a edição). São Paulo: Martins Fontes.

Bakhtin, M. (1986). Speech genres and other late essays (C. Emerson \& M. Holquist, Orgs.; V. W. McGee, Trad.). Austin: University of Texas Press.

Bakhtin, M. (2000). Estética da criação verbal (M. E. Galvão, Trad., 3a edição). São Paulo: Martins Fontes.

Bruner, J. (1997). Atos de significação (S. Costa, Trad.). Porto Alegre: Artes Médicas.

Bruner, J. (2001). Self-making and world making. In J. Brockmeier \& D. Carbaugh (Orgs.), Narrative and identity: studies in autobiography, self and culture (pp. 25-37). Amsterdan: John Benjamins.

Freeman, M. (1998). Mythical time, historical time, and the narrative fabric of the self. Narrative Inquiry, 8, 1-24.

Hermans, J. M. (1996). Voicing the self: from information processing to dialogical interchange. Psychological Bulletin, 119(1), 31-50.

Lightfoot, C. (1997). The culture of adolescent risk-taking. Nova York: Guilford.

MacIntyre, A. (1981). After virtue. South Bend, Indiana: University of Notre Dame Press.

Miller, P. J., Potts, R., Fung, H., Hoogstra, L., \& Mintz, J. (1990). Narrative practices and the social construction of self in childhood. American Ethnologist, 17(2), 292-311.

Nelson, K. (Org.). (1989). Narratives from the crib. Cambridge, Massachusetts: Harvard University Press.

Polkinghorne, D. (1988). Narrative knowing and the human sciences. Nova York: State University of New York Press.

Ricoeur, P. (1994). Tempo e narrativa (Tomo 1). Campinas, SP: Papirus.

Sarbin, T. (1986). The narrative as a root metaphor for psychology. In T. Sarbin (Org.), Narrative psychology: the storied nature of human conduct (pp. 3-21). Nova York: Praeger.

Valsiner, J. (2000). Culture and human development. Londres: Sage.

Vigotski, L. (2000). A construção do pensamento e da linguagem. São Paulo: Martins Fontes. 
${ }^{1}$ Agradecimentos ao CNPq pela bolsa de doutorado e à CAPES pela bolsa para estágio doutoral. O presente trabalho faz parte da tese de doutorado da primeira autora.

${ }^{2}$ Embora a versão brasileira de Tempo e Narrativa (Ricoeur, 1994) utilize a expressão intriga e tessitura da intriga, optamos pela nomenclatura correspondente: enredo e construção do enredo porque, do ponto de vista da metodologia de análise aqui ilustrada, o termo enredo está mais próximo da idéia de que o significado narrativo se refere à organização dos fatos da experiência numa rede: a trama narrativa. Por sua vez, o termo construção remete ao objeto específico deste estudo: a construção narrativa do significado. Neste sentido, a expressão construção do enredo, utilizada neste artigo, se aproxima mais da perspectiva abordada de que, na narrativa, o enredamento simbólico dos fatos da experiência é um processo de construção de significados encetado pela narrativa.

Anália Keila Ribeiro, doutora em Psicologia Cognitiva pela Universidade Federal de Pernambuco, é professora no Centro Federal de Educação Tecnológica de Pernambuco. Endereço para correspondência: Rua Esmeraldino Bandeira, 411, apto 302, Graças; Recife-PE; CEP 52 011-060. Tel.: (81) 3241-2385. E-mail: analiakeila@yahoo.com.br

Maria da Conceição Diniz Pereira de Lyra, doutora em Psicologia Experimental pela Universidade de São Paulo, é professora no Programa de Pós-Graduação em Psicologia Cognitiva da Universidade Federal de Pernambuco. E-mail: marialyra2005@yahoo.com.br 